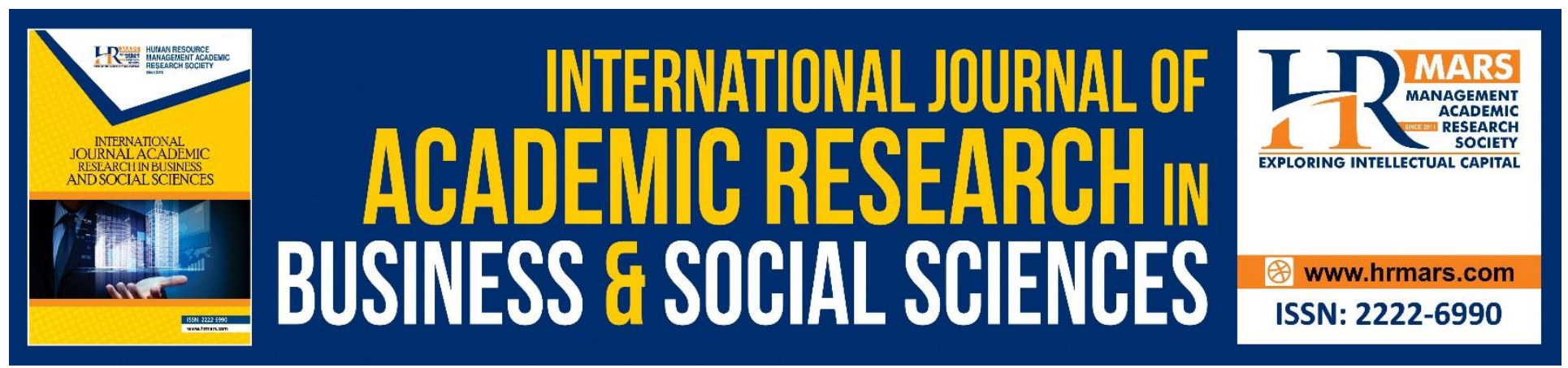

\title{
Enhancing Volunteerism in Healthcare: Mediating Effect of Social Network
}

\author{
Siti Noormi Alias, Maimunah Ismail, Turiman Suandi, Zoharah Omar
}

To Link this Article: http://dx.doi.org/10.6007/IJARBSS/v8-i12/5003

DOI: $10.6007 /$ IJARBSS/v8-i12/5003

Received: 09 Nov 2018, Revised: 07 Dec 2018, Accepted: 16 Dec 2018

Published Online: 18 Dec 2018

In-Text Citation: (Alias, Ismail, Suandi, \& Omar, 2018)

To Cite this Article: Alias, S. N., Ismail, M., Suandi, T., \& Omar, Z. (2018). Enhancing Volunteerism in Healthcare: Mediating Effect of Social Network. International Journal of Academic Research in Business and Social Sciences, 8(12), 155-177.

Copyright: (C) 2018 The Author(s)

Published by Human Resource Management Academic Research Society (www.hrmars.com)

This article is published under the Creative Commons Attribution (CC BY 4.0) license. Anyone may reproduce, distribute, translate and create derivative works of this article (for both commercial and non-commercial purposes), subject to full attribution to the original publication and authors. The full terms of this license may be seen

at: http://creativecommons.org/licences/by/4.0/legalcode

Vol. 8, No. 12, 2018, Pg. 155 - 177

http://hrmars.com/index.php/pages/detail/IJARBSS

JOURNAL HOMEPAGE

Full Terms \& Conditions of access and use can be found at http://hrmars.com/index.php/pages/detail/publication-ethics 


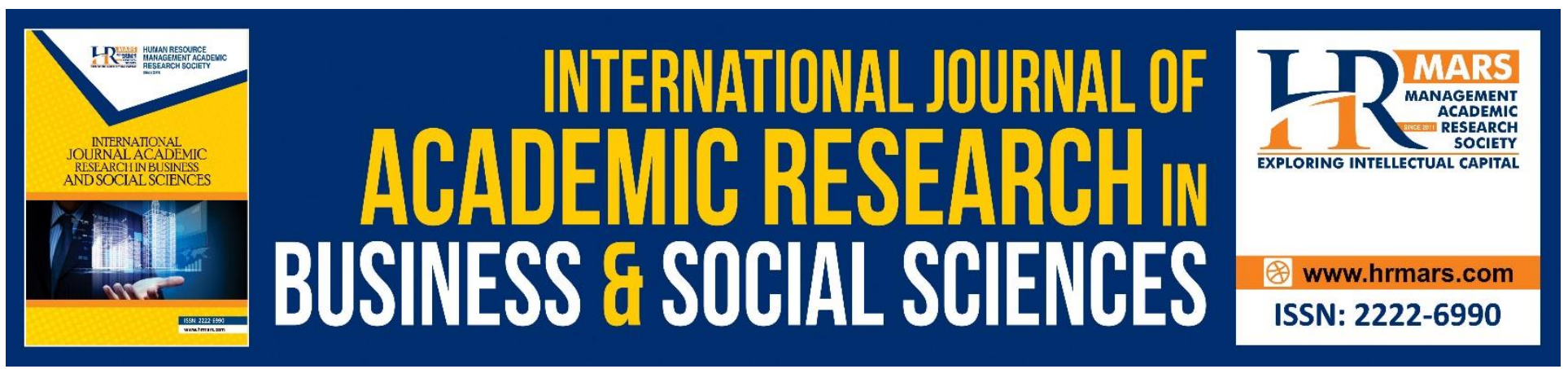

\title{
Enhancing Volunteerism in Healthcare: Mediating Effect of Social Network
}

\author{
Siti Noormi Alias, Maimunah Ismail, Turiman Suandi, Zoharah Omar \\ Faculty of Educational Studies, Universiti Putra Malaysia, 43400 UPM Serdang, Selangor Darul \\ Ehsan, Malaysia
}

\begin{abstract}
The participation of volunteers in volunteerism activities particularly in combating healthcare issues among underserved communities is highly demanded. Volunteerism refers to intangible contributions of time and effort spent to help those people in straitened circumstances in a community. Volunteerism is a type of philanthropic behavior. This study explored how social network acts as a mediator in the relationships between coping strategies and social trust with volunteerism. This study used a correlational research design involving 300 community health workers (CHWs) under MERCY Malaysia, a non-government organization (NGO) in the healthcare sector. Data were analysed using a two-step approach in structural equation modeling (SEM). Results showed that social network mediated the relationship between task-oriented coping and volunteerism in community healthcare. This study gives insights to managers and NGOs in hiring and retaining CHWs in community development work based on a developing country context.

Keywords: Volunteering, coping strategies, social trust, social network, community health workers
\end{abstract}

\section{Introduction}

Volunteerism in healthcare involves intangible contributions of time and effort by volunteers to help and improve the lives of the underprivileged community (Stukas et al., 2016). Volunteerism entails social interactions between various interacting units (stakeholders) in volunteering social network. Volunteering activities, which particularly monitored under non-profit and voluntary institutions, provide benefits not only to the victims but the volunteers themselves, the organization they serve, the local community, as well as the society at large. Victims will acquire the necessary healthcare relief, whilst in return, volunteers will be exposed to the improvement in terms of technical and social skills. Moreover, the organizations they serve will successfully achieve their vision and mission, the local community will grow in a healthy environment, and the society will flourish equally in the social system. Therefore, the promotion of volunteering is not just on individual consciousness for humanity, but it has become the community and national focus. In addition, volunteerism claim to be one of philanthropic initiatives other than donating, solely by individuals and organizations. 
Notwithstanding that the awareness on the importance of volunteerism in healthcare escalates, nonprofit organizations are still in constraints to hire new volunteers and to retain them in the workforce (Stukas et al., 2016).

In Malaysia context, it is estimated that for every 1,000 population, there are seven registered volunteers (Do Something Good, 2012). Therefore, for 23.9 million Malaysian population aged above 15 years old, there were 167,300 registered volunteers in Malaysia (Department of Statistics Malaysia, 2016). This makes up only $0.7 \%$ of the population involved in volunteerism in 427 nongovernmental organizations (NGOs). In average, 12,538 individuals are involved in healthcare volunteering activities. One of the NGOs in healthcare is MERCY Malaysia.

Throughout the deployment of human resources to face the outbreaks of diseases such as Suspected Severe Acute Respiratory Syndrome (SARS), Chikungunya, Ebola, human infection with avian influenza A (H7N9), and recently zika virus, Malaysian government strongly encourage the participation of NGOs in combating these healthcare issues particularly in urban areas. Related to this, the Malaysia's National Social Policy, which was established in 2003, prominently, showing the government continuous efforts and seriousness to provide equal development opportunities. It is done by providing opportunities to develop individuals' potentials to the optimum in a healthy social environment based on fairness and equity in accordance with the goal of Vision 2020. Moreover, government alone could not afford to provide sufficient health services to all citizens. Consequently, the involvement of various entities including NGOs and their volunteers in health-related activities is required to complement existing healthcare services provided by the government and thus be able to realize the national development goal.

The underlying motivations for volunteering may vary and articulating them facilitate the recruitment processes for new volunteers as well preserving the existing volunteers. However, these motivating factors are still not enough to secure the continuous involvement of the volunteers due to task complexities, particularly when volunteering in healthcare areas. Healthcare can be considered as one of the most highly demanding areas of volunteering work among victims and public, yet, it is extremely risky. For example, the political conditions of the affected areas (such as in Syria and Myanmar), the policies restrictions (i.e., Palestine, Sri Lanka, and Sudan), and the severity of injuries of victims, may somehow or rather, have psychological effects on these volunteers. To aid this process, the individual volunteers are strongly assured to have full control over any decision he will take which related to any voluntary involvement in healthcare activities. Therefore, it is necessary to include individual constituents into account.

Volunteerism in healthcare mostly deals with emergencies, lost, and injuries. In time of disaster, the mental health of the affected population may not be seen as an immediate need if compared to physical injuries. Traumatized survivors need emotional support and guidance in the aftermath of a disaster, and accordingly, psychosocial intervention from skilled volunteers are highly demanded. However, volunteers themselves also are human beings, in which if they were exposed to repeated traumatized and emergency cases for a long term, it may affect their physical and mental wellbeing (Cheung et al., 2016). For example, volunteers cannot enjoy their food as usual and do not get enough 
rest because their minds keep restoring about victims and corpses. Therefore, the way these volunteers deal with such obstacles to cope with the situations has become one of the focuses of this study because this issue is rarely being explored in the past.

Stukas et al. (2016) asserted that individuals joined voluntary works because of their desire to help others and to sustain their contributions. This relates to their adaptation to social challenges and volunteering work complexities in healthcare. As volunteerism in community healthcare deals with multiple emergency cases (i.e., earthquake, flood, and bloodshed incidents) and teamworks among members play a major role in accomplishing the task, these activities certainly require individuals with the most suitable coping style and high level of trustworthiness. Lazarus (1991) referred to coping as the way an individual deals with situation, which is challenging, threatening, harming, or even benefiting him. It can also be defined as conscious attempts to manage internal or external stressors that the individual perceives as over his limitations (Pavlova \& Silbereisen, 2014). Coping thus can be used to describe an individual adaptation to adverse social interaction circumstances. Coping in volunteering occurs when people sometimes engage in behavior which usually under social pressure such as repeated traumatic events experienced (Cicognani et al., 2009), and also frequent contact with victims (i.e., ill people or those with serious traumatic issues after events such as flood, earthquake, tsunami, aeroplane crash). These kind of situations definitely require great physical and emotional efforts to deal with. Task-oriented coping describes an active problem solving approach to stressful situations (Endler \& Parker, 1999). In contrast, emotional coping is characterized by engaging behaviors such as ruminating or becoming emotional in response to stress. Individuals who report a preference to avoid stressful situations have a predominantly avoidant coping strategy.

Social trust is one of the dimensions of social capital (other than social network and shared goals) that exists between human interactions and widely used to describe collaborative interactions in the community including volunteerism (Wing \& Lai, 2008). Social trust refers to the degree of one's willingness to the vulnerable actions of other people (Chow \& Chan, 2008). Based on these definitions, this study takes the meaning of social trust as an individual's belief that others will not do him harm and can be relied upon.

Social trust includes trust in other people and trust in organization by which it could increase individual tendency to actively engage and continuously involve in volunteering activities (Rothstein \& Uslaner, 2005). Kelly (2009) has shown that individuals who trust others (individuals and institutions) have more tendency to participate in volunteering activities. Meanwhile, according to Siegrist and Cvetkovich (2000), social trust will be utilized by individuals to select experts who are trustworthy and whose opinions believed to be accurate. Their study on the role of social trust depicted that there was a significant correlations $(r=.59)$ between social trust and individual decisions towards performing certain behavior in the absence of sufficient knowledge.

Indeed, volunteerism in healthcare is inseparable from the need for interactions in their social network. A volunteer social network may consist of multiple stakeholders including volunteers in the same organization and management team, volunteers from other organizations, as well as from government, private sector, and public at large. Good teamwork with other members will ensure a 
smooth work accomplishment, sturdy coalition with management team that can create efficient communication flow, and vigorous affiliation with volunteers from another organization, which can cultivate information exchange. In addition, strict adherence to government rules and regulations may secure funds, tenacious collaboration with private and government-linked organizations, which will increase the probability for sponsorship and will generate future philanthropists. Moreover, the intensified association with public as well as local communities will preserve continuity of human resources in the third sector. Due to the above reasons, these volunteers tend to maintain their contact and bond with others. As a result, individuals in their personal networks are homogenous with regards to their interest (i.e., volunteerism in healthcare), socio-demographic, behavioral, and interpersonal characteristics (McPherson et al., 2001). More importantly, the presence of homophily will influence information flows among the interacting units in a social network. The information obtained will be translated into actual behavior and later will be disseminated and impinged on others' behavior.

Consequently, fostering these homophilous connections among the stakeholders in social network can spread social wellbeing such that people will start trusting and be trustworthy to each other (van Ingen \& Bekkers, 2015). Accordingly, the volunteer role identification can be promoted and developed. Meanwhile, both volunteering and identity may arise from social trust (Bekkers \& Bowman, 2009). A reciprocal relationship exists between developing volunteer identity and social trust that will further enhance teamwork, which subsequently can provide outcomes such as volunteering behavior. Next, we demonstrate the research gap of the study.

Despite the crucial role of volunteers in community healthcare, little is known about the antecedents such as coping strategies and social trust, and the mediator such as social network in influencing their involvement in volunteering activities. Social network is chosen as a mediator because it is one of the dimensions of social capital. Social capital further signifies the strength of interaction among individual volunteers in the social system. The effect of social factor in the context of volunteerism in healthcare or even in volunteering as a whole in Malaysia is still underexplored. Against such a backdrop, several questions arise: How do individual coping strategies and social trust predict volunteerism in healthcare? How does social network mediate the relationships between coping strategies and social trust among volunteerism in healthcare? This study sought to answer these research questions. This study is significant because it adds knowledge on volunteering in healthcare from the perspective of NGO of a developing country. Therefore, this study aims to determine the mediating effect of social network in the relationships between coping strategies and social trust among volunteers in healthcare in Malaysia. The article continues with discussions on theoretical foundations, hypotheses development, research framework of the study, followed by methodology, and ends with a conclusion.

\section{Theoretical Foundation}

This study proposes two types of relationships that exist between the studied variables: a) direct relationships, b) indirect relationships through social network. We used two theories vis, the Theory 
of Planned Behavior (TPB) (Ajzen, 1991) and Social Network Theory (SNT) (Granovetter, 1973) to underpin the theoretical framework.

TPB is the most significant theory in predicting actual action (Lu et al., 2009) including volunteerism. This theory is guided by three considerations: beliefs about the likely consequences of the behavior (behavioral beliefs), beliefs about the normative expectations of others (normative beliefs), and beliefs about the presence of factors that may affect performance of the behavior (control beliefs). These beliefs might be influenced by various individual's background factors including mood, coping, social trust, and experiences (Ajzen, 2005). Briefly, it can be said that all the relationships between background factors and particular behavior can be examined directly and not necessarily through behavioral, normative, and control beliefs. This further justifies the direct relationships between two groups of background factors (coping strategies and social trust) and the studied behavior (volunteerism).

In addition, the more favorable the attitude and subjective norm, and the greater the perceived control, the stronger the person's intention should be in performing the behavior. Given a sufficient degree of actual control over the behavior, people are expected to carry out their intentions when opportunity arises. For example, if a person intends to engage in volunteerism, he or she will likely be involved in an actual behavior such as voluntarily attached to any volunteering institution. Following this suggestion, intention and actual behavior will be treated equally. Example of studies that employed similar theory and interchangeably used intention or behavior in referring to particular behavioral outcomes include, Courneya et al.'s (1999) study on the relationship between personality and exercise behavior, Manning and Bettencourt's (2011) study on depression and medication adherence among breast cancer survivors, and Cordano and Frieze's (2000) study on pollution reductions among environmental managers. Based on the above descriptions, TPB is employed into this investigation to explain the relationships between coping strategies and social trust with volunteerism in healthcare.

Social network is a set of actors (nodes) connected together by social relations (ties). The actors possibly are individuals, groups, organizations, or communities. Whereas, ties may fall within a level of analysis (e.g., individual-to-individual ties) or cross-levels of analysis (e.g., individual-to-group ties) (Katz et al., 2004). There can be flows and exchanges between the interacted nodes. Flows and exchanges can be very important in network theory as both can affect human behavior. Amongst the earliest scholars of SNT, is Granovetter (1973) who proposed that: a) behavior is shaped and constrained by one's network, and b) individuals can manipulate these social networks to achieve specific goals.

SNT rests on the notion that the social structure and functioning of the network may influence individual behavior and attitudes by shaping access to opportunities and constraints on behavior (Forthofer et al., 2016). Networks are believed to operate at the behavioral level through four primary pathways: social support, social influence, social engagement and attachment, and access to resources and material goods (Berkman \& Glass, 2000). Social support interventions help change 
behavior through building, strengthening, and maintaining social networks that provide supportive relationships for behavioral change, which one of it is towards volunteering.

Social life is created by relations and the patterns formed by these relations. Therefore, SNT is able to explain the process of mapping and measuring relationships and flow among people, groups, or organizations, where they mostly shared the similar attributes (Nour, 2011). Asendorpf and Wilpers (1998) emphasized that dyadic social relationships formed resulting from the transaction between two individuals. In accordance, individuals develop in a dynamic, continuous, and reciprocal process of interaction with their environment. However, the quality of social relationship between the members in a social network is a function of the individual characteristics (Westaby, et al., 2016). For example, sociable individuals may actively create opportunities for new relationship by spending more time with others and agreeable persons may minimize interpersonal conflict by being less aggressive or by provoking less aggression from others.

\section{Hypotheses Development}

Hypotheses are now proposed building on the previous discussion, including coping strategies, social trust, and social network with volunteerism in healthcare.

H1: Task-oriented coping is significantly associated with volunteerism in healthcare.

H2: Emotion-oriented coping is significantly associated with volunteerism in healthcare.

H3: Avoidance-oriented coping is significantly associated with volunteerism in healthcare.

The most robust coping strategies found in literature comprised of three construct, namely task, emotion, and avoidance-oriented coping (McWilliams et al., 2003). Coping strategies have yet to be investigated in relation to volunteerism in healthcare. There is very limited evidence on which to base our hypothesis. In addition, most studies on coping strategies among volunteers in healthcare only differentiate the most preferable coping style based on genders and number of years served (i.e., Essex \& Scott, 2008) and the general ways of reducing the effect of stressful situations (i.e., attending religious activities) without specifically classified them into the standardized types of coping strategies.

Electing the most appropriate coping style when dealing with challenging situations would reduce any adverse impact (i.e., physically and mentally) towards victims and volunteers themselves. Taskoriented strategy is associated with optimism, enjoys being around people, and easily adapt with social changes (Grove \& Heard, 1997). Meanwhile, emotion-oriented strategy associated with individual endeavour to reduce the amount of stress by modifying his emotional responses to stressor. For that reason, the first two coping strategies were considered as proactive way to deal with challenging situations and contributed to better adjustment. By contrast, avoidance coping style is related to maladaptation due to inclinations towards framing and avoiding himself from the problems encountered. Thus,

H4: Social trust is significantly associated with volunteerism in healthcare. 
Social trust includes trust in other people and trust in organization by which it could increase individual tendency to actively engage and continuously involve in volunteerism (Rothstein \& Uslaner, 2005). In fact, it has been proven in a study conducted by Kelly (2009) among youth ages ranging from 15-25 years, which shows that individuals who trust others resulted the government have more participation tendencies. Delhey and Newton (2003) suggested that social trust contributes to the provision of public goods, social integration, cooperation and harmony, and even to good health and longevity. Consequently,

H5: Social network is positively associated with volunteerism in healthcare.

Social interaction is essential for every humankind. Volunteers with extensive social networks, involve in multiple organizational memberships, and prior volunteer experience can increase the chances of continuously contribute to society through volunteerism in healthcare (Wilson, 2000). This simply means that social network (breadth and strength) can be a predictor of volunteerism. Fowler and Christakis (2010) asserted that a wide variety of behaviors spread in human social networks particularly when they choose to be friend with people of similar behavior. They further suggested that dyadic social interactions in particular social network attract individuals to behave the same way as shown by fellow group members. Through such process or known as socialization process, an individual acquires attitudes, behavior, and knowledge needed to be accepted in certain social network (Morrison, 2002). They added that a sense of giving to others through volunteerism could emerge as a result of repeated interactions in a fixed social network because of "social viscosity". Therefore, this research hypothesizes that:

H6: Social network mediates the relationship between task-oriented coping and volunteerism in healthcare.

H7: Social network mediates the relationship between emotional-oriented coping and volunteerism in healthcare.

H8: Social network mediates the relationship between task-oriented coping and volunteerism in healthcare.

H9: Social network mediates the relationship between social trust and volunteerism in healthcare.

Proactive coping strategies and social trust are shown to positively influence social competence (Kaeppler \& Erath, 2016). Social competence can be proved by the size and strength of social network. Regular interactions between the interacting units in similar social network (homophile) prone to involvement in volunteering activities in healthcare. Previous studies have indicated that social network have a mediating effect. For example, Cattell (2001) qualitative study on the dynamics between poverty and exclusion, found that social network mediated the relationship between individual factors (i.e., violent) and expression of feelings associated with health outcome. Other studies that employed social network as mediating variable are by Kaskutas et al. (2002), on the relationship between alcoholics anonymous involvement and reduced substance use; Ahimbisibwe et al.'s (2012) study on the mediating role of social network dimensions (i.e., network degree and network transitivity) on the relationship between project communication strategies and perceived 
INTERNATIONAL JOURNAL OF ACADEMIC RESEARCH IN BUSINESS AND SOCIAL SCIENCES Vol. 8, No. 12, Dec, 2018, E-ISSN: 2222-6990 C 2018 HRMARS

project success. These studies revealed that social network is a significant mediator in the relationship between variables being studied. Hence, this study hypothesizes that:

Based on the above literature review and hypotheses, Figure 1 shows the hypothesized framework of the study.

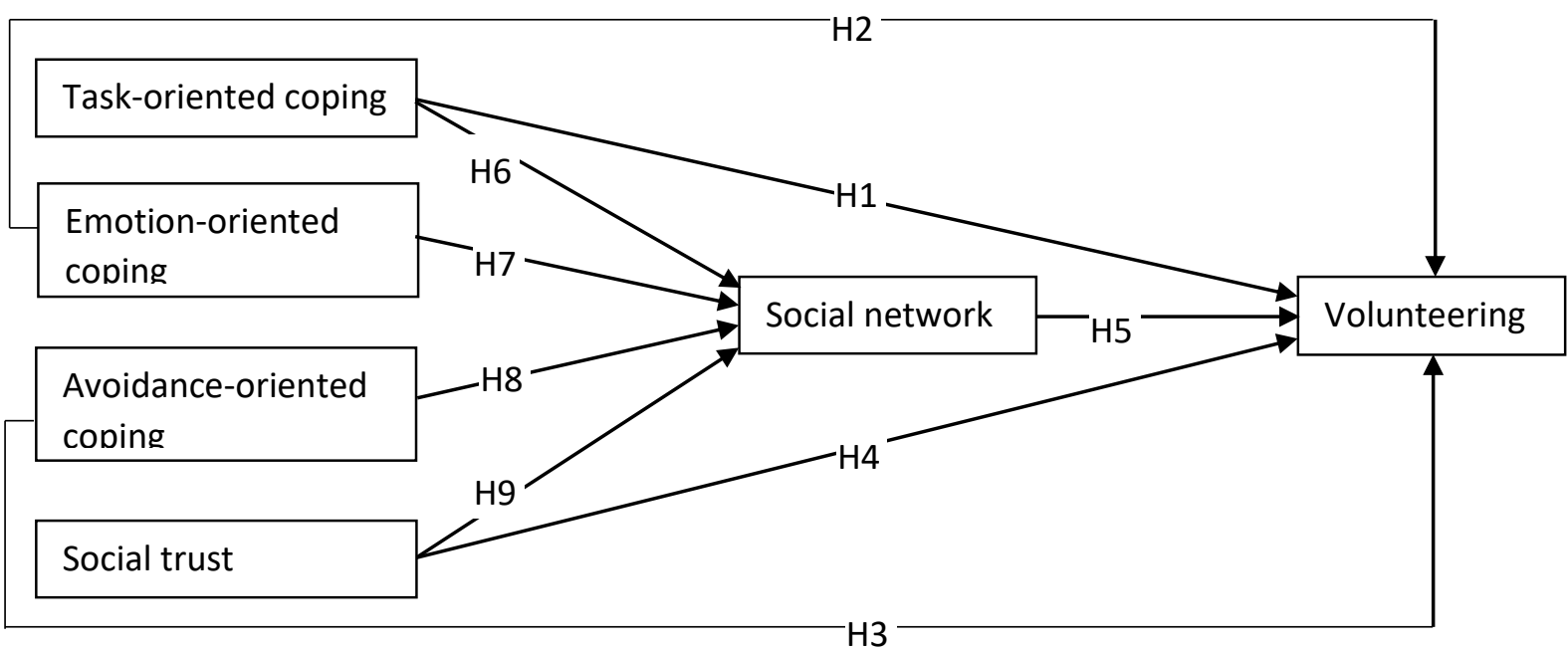

Figure 1. The Hypothesized Research Framework

\section{Methodology}

\section{Design and Participants}

The study employed correlational research design. The subject of the study were the registered volunteers under the MERCY Malaysia who were categorized as active volunteers $(N=1,200)$. MERCY Malaysia is an international Malaysian-based NGO focusing on providing medical relief, sustainable health-related development, and risk reduction activities for vulnerable local and international communities (i.e., Sri Lanka, Somalia, Philippines, and Myanmar). CHWs from MERCY Malaysia were chosen as the participants of this study due to several reasons: i) its significance in offering assistance to the needy based on philanthropic philosophy; ii) the personnel of this NGO are genuine volunteers despite having their formal functions in their respective organizations such as hospitals, clinics, companies, and Universities; and iii) the functions of the volunteers are on a wide spectrum of community health services.

The sample consisted of medical $(n=84)$ and non-medical $(n=216)$ volunteers recruited through online questionnaire (http://esurv.org/onlinesurvey.php?surveyID=LIKHLF 6d54b664\&u=philanthropic behavior) developed by the research team. The administration of the questionnaire was facilitated by the MERCY Malaysia management team. The questionnaire was prepared in both English and Malay languages to meet respondents' preferences. The accuracy of the translation in both languages was assured through the services of two language experts in Malay and English. The volunteers' age ranged from 18 to 74 years old ( $M=$ 
INTERNATIONAL JOURNAL OF ACADEMIC RESEARCH IN BUSINESS AND SOCIAL SCIENCES

Vol. 8, No. 12, Dec, 2018, E-ISSN: 2222-6990 @ 2018 HRMARS

28.69, SD = 9.54), were single (62.7\%), and mostly female (60.7\%). Data collection took place between 1 February and 31 July 2015. The sampling technique used was simple random sampling in Microsoft Excel.

\section{Measures}

Dependent variable. This study used instrument from Canadian National Survey of Giving, Volunteering, and Participation (NSGVP) to measure volunteerism's construct. Volunteers responded to items such as "in the past 12 months, how frequently did you involve in issues related to health screenings, such as breast cancer screening, pap smears, glaucoma tests, or diabetes screenings as a volunteer?" on a scale of 1 (very rarely) to 5 (very frequently).

Mediator. As for social network, we adapted items developed by Kaskutas et al. (2002) and Overall Connectedness Dimensions by Van Bel et al. (2009). The 12 statements, including "I have a large circle of friends linked with my volunteer activities", were responded to on 5-point Likert-like scale ranging from 1 (strongly disagree) to 5 (strongly agree). Two negatively worded items were reverse-scored.

\section{Independent Variables}

Coping strategies. This study employed Coping Inventory for Stressful Situations (CISS) to measure coping strategies among volunteers. Volunteers responded to 21 items (seven items for each coping strategies) on a scale of 1 (strongly disagree) to 5 (strongly agree). Example of item used to measure task-oriented coping is "When encountering problems, I focus on the problem and see how I can solve it", example of item for emotional-oriented coping "when encountering problems, I blame myself for having gotten into this situation" and "when encountering problems, I take some time off and get away from the situation" is example of item for avoidance-oriented coping.

Social trust. We utilized General Trust Scale by Yamagishi et al. (1998) to measure volunteers' social trust. Respondents were required to answer six statements on general trust items such as "most people are basically honest" and were recorded based on their level of agreement.

\section{Statistical Analyses}

This study used IBMSPSS22 to analyze demographic components and the correlations (Pearsonproduct moment correlation) between the studied variables. Regression models were estimated through structural equation modeling (SEM) using AMOS to determine the effects of the hypothesized variables based on bootstrapping formula by Preacher and Hayes (2004). As suggested by Hayes (2009), this study requested 5,000 bootstrap samples and requested for $95 \%$ confidence intervals for Bias-corrected option. The last column of Table 3 shows the upper and lower limits for the $95 \%$ confidence intervals. These values correspond to the 2.5 th and 97.5 th percentiles from lowest to highest rank-ordered estimates of the indirect effect derived from the 5,000 samples.

In accordance, the determination of mediation effect of social network in the relationships between IVs and DV strictly follows the rules suggested by Preacher and Hayes (2004). This study used Preacher and Hayes (2004) determination of mediation effect over the traditional rule by Baron and 
Kenny (1986) due to one of the foremost recent argument raised by scholars in literature. Baron and Kenny (1986) asserted that the evidence for mediation is strongest when there is an indirect effect, which they call "full mediation." When there are both indirect and direct effects, they call it "partial mediation." However, according to lacobucci (2008), majority of articles that strictly follow Baron and Kenny (1986) mediation test steps ended up with 'partial mediation'. That is, mediation is usually accompanied by a direct effect. Therefore, truthfully there is a grounding direct relationships between set of IVs and DV that sometimes hard to be explained theoretically. Thus, there is a need for more practical ways to test for mediation effect becomes possible without putting the requirement for significant direct relationship (between IVs and DV) comes first.

Mediation based on Preacher and Hayes (2004) is equal to the indirect effect, regardless whether there is or not direct relationship between independent and dependent variables. Mediation is said to be significant as long as it is proven that the indirect effect of independent variable on dependent variable through mediator is significant. The determination of mediation effect of social network on the relationships between coping strategies (task-oriented, emotion-oriented, and avoidanceoriented) and social trust with volunteering in this study is based on "zero" location in $\mathrm{Cl}$ (Hayes, 2009). It states that if $\mathrm{Cl}$ contains "zero" means indirect or mediation effect is statistically significant. In addition, calculated effect size (kappa-squared, $\mathrm{k}^{2}$ ) for significant indirect effect based on Preacher and Kelley (2011) is also available. They suggested that it makes sense to interpret $k^{2}$ values in the same light as the coefficient of determination $\left(R^{2}\right)$, i.e., with the guidelines of Cohen (1988), where small, medium, and large effect sizes are stated as $0.01,0.09$, and 0.25 , respectively. The $k^{2}$ values were calculated based on values of variance of independent variables (X), mediator (M), and dependent variable (Y), covariance of $X Y, X M$, and $M Y$, Beta of $X$ on $M(a)$, Beta of $M$ on $Y(b)$ as in Myresearchsurvey.com developed by Rothmann (2011).

The following parameters were considered to determine the model fit for both measurement and structural models in SEM analyses: factor loading $>.50$, Relative $x^{2}<5.0$, the root mean square error of approximation (RMSEA) <.08, Akaike's information criterion (AIC) in which lower is better, the goodness of fit index (GFI) >.90, the adjusted goodness of fit index (AGFI) >.90, the comparative fit index $(\mathrm{CFI})>.90$, the incremental fit index $(\mathrm{IFI})>.90$, and Tucker-Lewis index $(\mathrm{TLI})>.90$.

Table 1 shows factor loadings, average variance extracted (AVE), and construct reliability of the scales used in this study. Factor loadings of all items met the minimum cut-off point .50, and .70 for construct reliability. Hair et al. (2005) suggested that greater than 0.5 AVE reveals that the construct has higher reliability. However, the AVE for the volunteerism, social network, task-oriented coping, and social trust constructs are below the minimum cut off point of 0.5 , which may suggest that the validity for these four constructs is compromised. A new sample is needed in the future to confirm our conclusion. 
INTERNATIONAL JOURNAL OF ACADEMIC RESEARCH IN BUSINESS AND SOCIAL SCIENCES Vol. 8, No. 12, Dec, 2018, E-ISSN: 2222-6990 @ 2018 HRMARS

Table 1: Factor Loadings, Average Variance Extracted, and Construct Reliability of Scales

\begin{tabular}{|c|c|c|c|}
\hline Items & $\begin{array}{l}\text { Factor Loadings } \\
(r>0.5)\end{array}$ & $\begin{array}{l}\text { AVE } \\
(\text { AVE }>0.5)\end{array}$ & $\begin{array}{l}\text { Constr } \\
\text { Reliab } \\
\text { (CR>0. }\end{array}$ \\
\hline \multicolumn{4}{|c|}{ Volunteerism } \\
\hline - Item 1 & .575 & 0.444 & 0.847 \\
\hline - Item 2 & .700 & & \\
\hline - Item 3 & .602 & & \\
\hline - Item 4 & .742 & & \\
\hline - Item 5 & .613 & & \\
\hline - Item 6 & .678 & & \\
\hline - Item 7 & .734 & & \\
\hline \multicolumn{4}{|c|}{ *1 item deleted } \\
\hline \multicolumn{4}{|c|}{ Social Network } \\
\hline - Item 1 & .595 & 0.395 & 0.866 \\
\hline - Item 2 & .656 & & \\
\hline - Item 3 & .504 & & \\
\hline - Item 4 & .680 & & \\
\hline - Item 5 & .612 & & \\
\hline - Item 6 & .644 & & \\
\hline - Item 7 & .645 & & \\
\hline - Item 8 & .597 & & \\
\hline - Item 9 & .709 & & \\
\hline - Item 10 & .620 & & \\
\hline \multicolumn{4}{|c|}{ *2 items deleted } \\
\hline \multicolumn{4}{|c|}{ Task-oriented Coping } \\
\hline - Item 1 & .642 & & \\
\hline - Item 2 & .686 & 0.459 & 0.771 \\
\hline - Item 3 & .743 & & \\
\hline - Item 4 & .632 & & \\
\hline *3 items c & & & \\
\hline
\end{tabular}


INTERNATIONAL JOURNAL OF ACADEMIC RESEARCH IN BUSINESS AND SOCIAL SCIENCES Vol. 8, No. 12, Dec, 2018, E-ISSN: 2222-6990 @ 2018 HRMARS

\begin{tabular}{llll}
\hline Items & $\begin{array}{l}\text { Factor Loadings } \\
(\mathbf{r}>\mathbf{0 . 5 )}\end{array}$ & $\begin{array}{l}\text { AVE } \\
\text { (AVE>0.5) }\end{array}$ & $\begin{array}{l}\text { Construct } \\
\text { Reliability } \\
\text { (CR>0.7) }\end{array}$ \\
\hline Emotional-oriented Coping & & & \\
- Item 1 & .759 & 0.591 & \\
- Item 2 & .852 & \\
- Item 3 & .772 & & \\
- Item 4 & .722 & & \\
- Item 5 & .732 & \\
*2 items deleted & & & \\
& & & \\
Avoidance-oriented coping & & & \\
- Item 1 & .786 & & \\
- Item 2 & .717 & & \\
- Item 3 & .716 & & \\
- Item 4 & .6804 & \\
- Item 5 & .632 & & \\
- Item 6 & .743 & & \\
- Item 7 & .686 & & \\
Social Trust & & & \\
- Item 1 & & & \\
- Item 2 & & & \\
- Item 3 & & & \\
- Item 4 & & & \\
- Item 5 & & & \\
*1 item deleted & .6900 & \\
\hline
\end{tabular}

Regarding discriminant validity to assess whether the constructs are sufficiently distinct from each other, Table 2 indicates that the value of square root of AVE for all latent constructs were higher than the correlation coefficient between the focal and other constructs. Accordingly, it testified the "reasonableness" of the constructs used in this study. 
INTERNATIONAL JOURNAL OF ACADEMIC RESEARCH IN BUSINESS AND SOCIAL SCIENCES

Vol. 8, No. 12, Dec, 2018, E-ISSN: 2222-6990 @ 2018 HRMARS

Table 2: Mean, Standard Deviation, Average Variance Extracted, Correlation Matrix, and Discriminant Validity of the Latent Constructs

\begin{tabular}{llllllllll}
\hline Constructs & Mean & SD & AVE & $\mathbf{1}$ & $\mathbf{2}$ & $\mathbf{3}$ & $\mathbf{4}$ & $\mathbf{5}$ & $\mathbf{6}$ \\
\hline Volunteerism & 4.218 & .556 & 0.444 & .780 & & & & & \\
Social network & 4.176 & .516 & 0.395 & $.546^{* *}$ & .707 & & & & \\
Task-coping & 4.110 & .558 & 0.459 & $.393^{* *}$ & .438 & .812 & & & \\
Emotional-coping & 4.140 & .461 & 0.591 & -.063 & .026 & .026 & .755 & & \\
Avoidance-coping & 3.702 & .765 & 0.504 & .042 & -.034 & .037 & -.007 & .718 & \\
Social trust & 3.732 & .660 & 0.447 & -.083 & -.032 & .017 & -.188 & -.155 & .799 \\
\hline
\end{tabular}

**. Correlation is significant at the 0.01 level (2-tailed).

Note: The squared root of AVE of each construct presented on the diagonal and correlation coefficients are located on the correlational matrix.

\section{Results}

Table 3 shows the results of fit indices for the structural model. Hooper et al. (2008) suggested that the researcher should choose the fit indices that indicate the best fit. Furthermore, Hult, et al. (2006) stated that most studies reported at least three fit measures together with RMSEA and $x^{2} / x^{2} / d f$. Meanwhile, value close to .90 reflects a good model fit (Schumacker \& Lomax, 2016). Therefore, according to results displayed in Table 3 , it was indicated acceptable fit for structural model.

Table 3: Goodness of fit Indices of Structural Model

\begin{tabular}{|l|l|l|l|l|l|l|}
\hline $\begin{array}{l}\text { Goodness } \\
\text { of Fit Index }\end{array}$ & CMIN $\left(x^{2}\right)$ & $\begin{array}{l}\left(x^{2} / \mathbf{d f}\right) \\
\mathbf{5 . 0}\end{array}$ & $\mathbf{C F I} \geq \mathbf{. 9 0}$ & IFI $\geq .90$ & TLI $\geq .90$ & RMSEA $\leq .08$ \\
\hline Value & 1330.59 & 1.66 & .91 & .92 & .91 & .05 \\
\hline
\end{tabular}




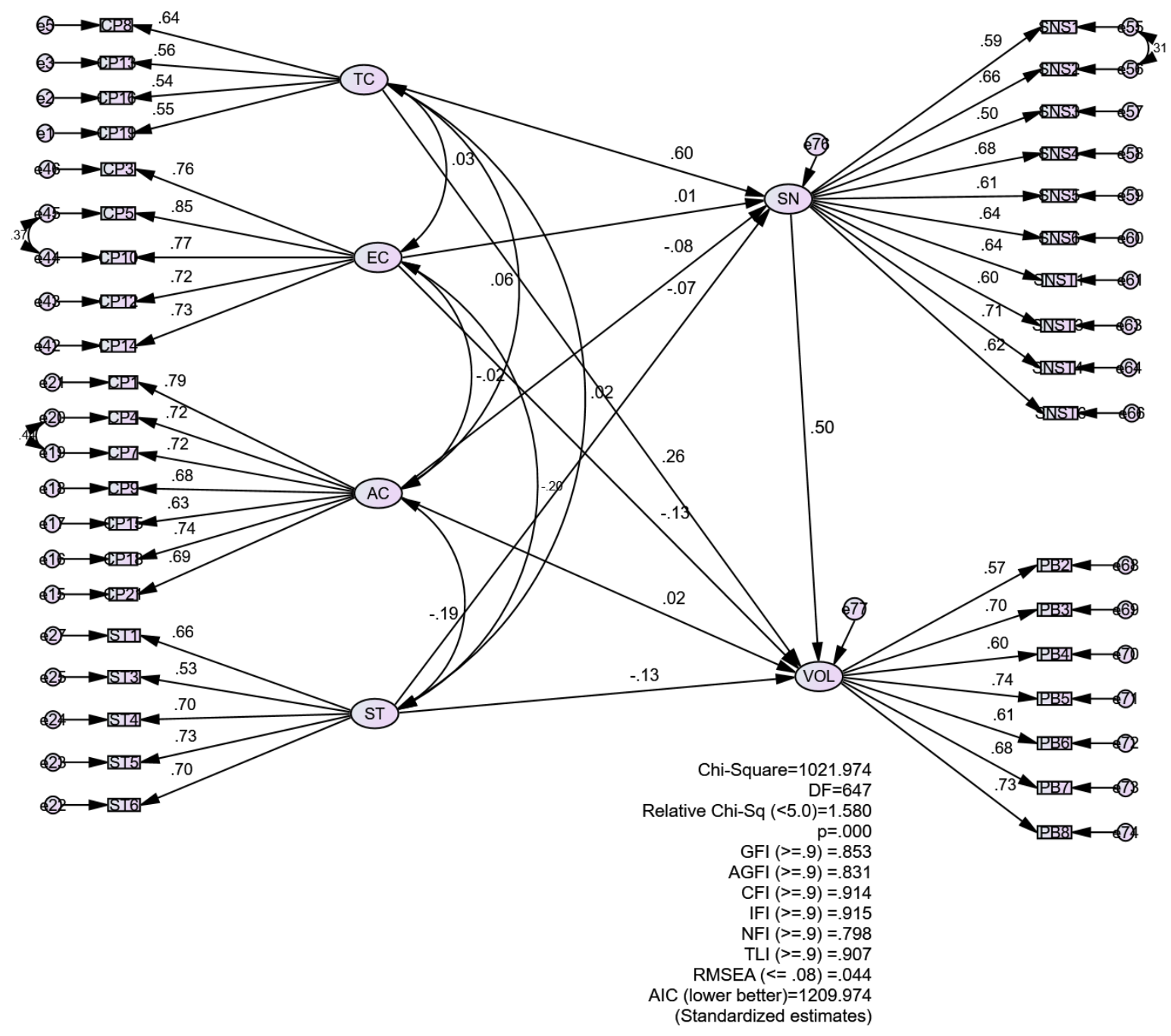

Figure 2. The Mediation Model of the Study

Table 4 illustrates that task-oriented and emotional-coping significantly influenced volunteerism in healthcare $(\beta=.264, p=.005 ; \beta=-.129, p=.020)$. The results also indicated significant relationship between social network and volunteerism in healthcare $(\beta=.497, p=.000)$. Except for emotionaloriented coping, the results of correlational matrix showed in Table 2 support the findings for relationships between task-oriented coping and social network with volunteerism in healthcare $(r=$ .546, $p<.01 ; r=.393, p<.01$ ). Consequently, the results support Hypothesis 1, Hypothesis 2, and Hypotheses 5. However, as for the direct relationships between avoidance-oriented coping and social trust with volunteerism, this study failed to provide enough evidences to reject the null hypotheses $(\beta=.024, p=.665 ; \beta=-.126, p=.091)$.

Table 4: The Regression Weights in the Direct Hypothesize Model 
INTERNATIONAL JOURNAL OF ACADEMIC RESEARCH IN BUSINESS AND SOCIAL SCIENCES Vol. 8, No. 12, Dec, 2018, E-ISSN: 2222-6990 @ 2018 HRMARS

\begin{tabular}{lllllll}
\hline No. & Hypothesized relationship & Beta & B & S.E. & C.R. & $\boldsymbol{p}$-value \\
\hline 1 & Task-oriented coping $\rightarrow$ Volunteerism & .264 & .291 & .103 & 2.835 & .005 \\
2 & Emotional-oriented coping $\rightarrow$ Volunteerism & -.129 & -.143 & .061 & -2.323 & .020 \\
3 & Avoidance-oriented coping $\rightarrow$ Volunteerism & .024 & .016 & .038 & .434 & .665 \\
4 & Social trust $\rightarrow$ Volunteerism & -.126 & .081 & .048 & 1.689 & .091 \\
5 & Social network $\rightarrow$ Volunteerism & .497 & .566 & .111 & 5.096 & .000 \\
\hline
\end{tabular}

As shown in Figure 2 and Table 5, the results indicated that there is a significant mediating effect of social network on the relationship between task-oriented coping and philanthropic behavior of volunteering [the bias-corrected $95 \%$ percentile confidence interval $(\beta=0.29, \mathrm{Cl}=0.19,0.46, p=.00$ ) and percentile $95 \%$ confidence interval $(\beta=0.29, \mathrm{Cl}=0.18,0.45, p=.00)$, both does not include zero]. In addition, following Preacher and Kelley (2011), we can conclude that the indirect effect of taskoriented coping on volunteerism through social network is large, $k^{2}=0.28^{*}$. Therefore, Hypothesis 6 was supported by bootstrapping analysis.

Table 5: Mediation of the effect of Individual Adaptability and Organizational Factors on Philanthropic Behavior through Social Network

\begin{tabular}{|c|c|c|c|c|c|c|c|c|}
\hline & \multirow{3}{*}{$\begin{array}{l}\text { Point } \\
\text { estimate }\end{array}$} & \multirow[t]{3}{*}{ SE } & \multicolumn{2}{|c|}{ Bootstrapping } & \multirow[t]{3}{*}{$P$} & \multirow{2}{*}{\multicolumn{2}{|c|}{$\begin{array}{l}\text { Bootstrapping } \\
\text { Percentile 95\% Cl }\end{array}$}} & \multirow[t]{3}{*}{$P$} \\
\hline & & & \multicolumn{2}{|c|}{$\begin{array}{l}\text { BC Percentile 95\% } \\
\mathrm{Cl}\end{array}$} & & & & \\
\hline & & & Lower & Upper & & Lower & Upper & \\
\hline $\begin{array}{l}\text { Task-oriented } \\
\text { coping }\end{array}$ & .297 & .055 & .199 & .416 & .000 & .197 & .414 & .000 \\
\hline $\begin{array}{l}\text { Emotion-oriented } \\
\text { coping }\end{array}$ & .004 & .032 & -.059 & .070 & .891 & -.059 & .070 & .882 \\
\hline $\begin{array}{l}\text { Avoidance- } \\
\text { oriented coping }\end{array}$ & -.041 & .035 & -.112 & .025 & .210 & -.109 & .027 & .226 \\
\hline Social trust & -.037 & .034 & -.109 & .026 & .246 & -.106 & .030 & .283 \\
\hline
\end{tabular}

However, for the emotion-oriented coping [the bias-corrected $95 \%$ percentile confidence interval $(\beta$ $=-.03, \mathrm{Cl}=-.08, .01, p=.13)$ and percentile 95\% confidence interval $(\beta=-.03, \mathrm{Cl}=-.08, .01, p=.15)$, both does include zero], avoidance-oriented coping [the bias-corrected $95 \%$ percentile confidence interval $(\beta=-.04, \mathrm{Cl}=-.11,0.01, p=.08)$ and percentile $95 \%$ confidence interval $(\beta=-.04, \mathrm{Cl}=-.11$, $.01, p=.11$ ), both include zero], and social trust [the bias-corrected $95 \%$ percentile confidence interval $(\beta=-.01, \mathrm{Cl}=-.03, .02, p=.67)$ and percentile $95 \%$ confidence interval $(\beta=-.01, \mathrm{Cl}=-.03, .02$, $p=.68$ ), both does not include zero], results showed that there were no significant mediating effect of social network between these three factors with philanthropic behavior of volunteering. Therefore, Hypothesis 7, Hypothesis 8, and Hypothesis 9, were not supported by the results of the bootstrapping analysis. 
INTERNATIONAL JOURNAL OF ACADEMIC RESEARCH IN BUSINESS AND SOCIAL SCIENCES Vol. 8, No. 12, Dec, 2018, E-ISSN: 2222-6990 @ 2018 HRMARS

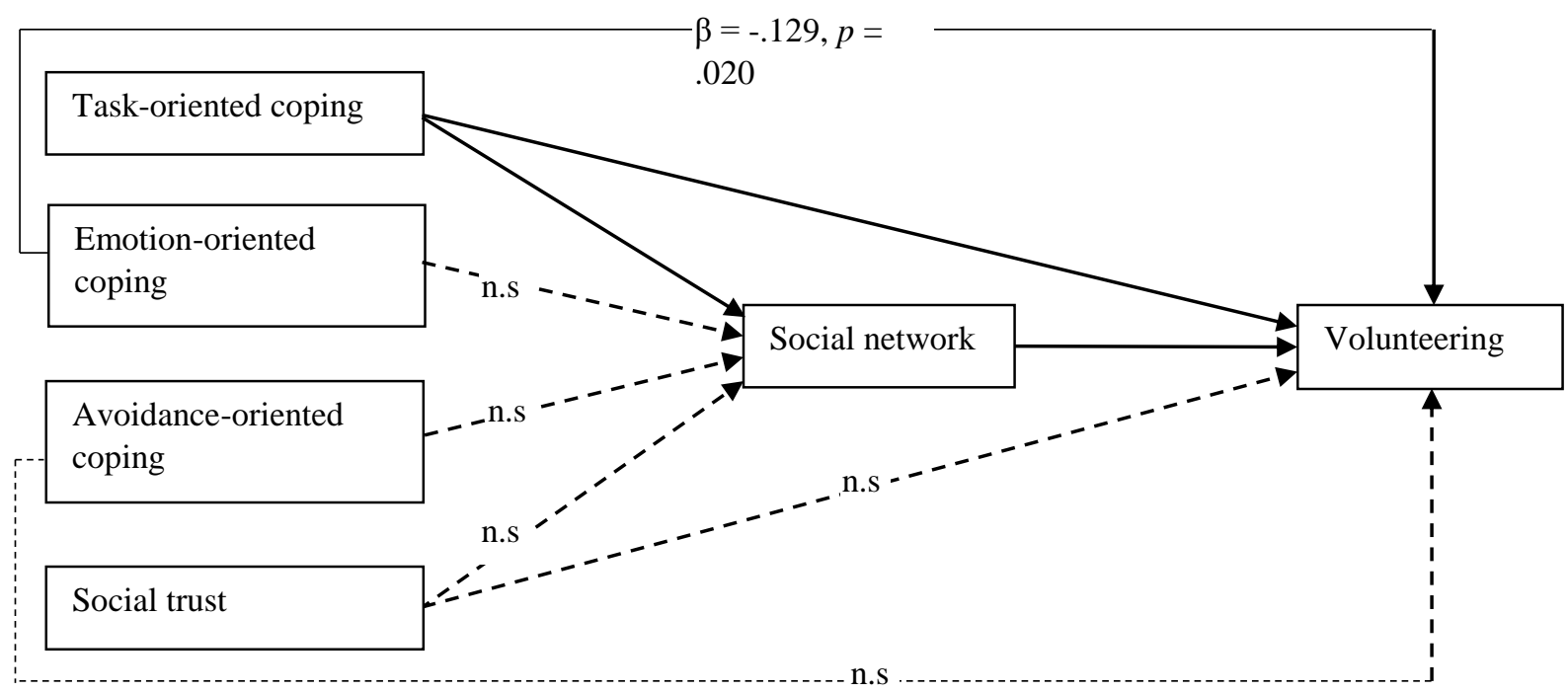

Figure 3. Summary Results of Direct and Indirect Relationships

\section{Discussion}

We found that there is a significant mediating effect of social network between the relationship of task-oriented coping and philanthropic behavior of volunteering. This means the volunteers believed that volunteering was the result of their social interaction with others such as colleagues and the significant others with similar volunteering interest, while doing their assigned tasks. Basing on the Social Network Theory perspective, individuals who regularly practiced positive task-coping styles make use of his social network to be exposed to new information about community work in healthcare. Furthermore, Cattell (2001) asserted that task-oriented coping contributes to dense and strong social ties, in which it enables likelihood for behavioral change, resulted from initial information exchange among the interacted unit. Information might be available from his kinship, parents, and relatives through personal communications, as well as through peers from social media such as Facebook, Twitter, and Instagram, that are currently pervasively used among the younger generation workers. As such, individuals connect, contact, interact, and get immediate responses regarding volunteering tasks in healthcare. As a result, active participation in formal social network does result in involvement of CHWs. Nevertheless, not all social networks lead to similar effects, although the number of social network per se has a positive effect on philanthropic behaviour of volunteering. Arun et al. (2015) suggested that those affiliated with heterogeneous network have a positive effect on increasing volunteering behavior in community healthcare. However, without early information, supports, and directions by his social network, the relationship between task-oriented coping and involvement in volunteerism in healthcare will not be possible. The explanations given supported the indirect relationship between task-oriented coping with volunteerism in healthcare through social network. This is consistent with previous literature stated that a size and strength of social network could account for a significant amount of variance in the relationship between taskoriented coping strategy with volunteerism in healthcare of CHWs in their respective study contexts (i.e., Arun et al., 2015). 
This study has a number of theoretical and practical implications. First, this study provides empirical evidence to support the crucial role of social network as an intervening factor (Finnigan et al., 2013) using the SNT. The theory further implies that a person will put in much effort to behave philanthropically specifically in volunteering when he formally attached to a community-based group, particularly in this study, MERCY Malaysia or probably other similar NGOs. Second, the study implies that social network has a certain influence and pressure on individual participation (Kaskutas et al., 2002), as the volunteering behavior spread out from social interaction. Thus, this study contributes to the theory by adding empirical evidence on the mediating function of social network towards volunteering philanthropic activities based on perception of CHWs in a Malaysian context, albeit limited to the influence of task-oriented coping factor. Third, this study provides evidence for NGOs to promote volunteering activities among the public, particularly in community healthcare services by emphasizing the crucial role of social network while not neglecting the role of task-oriented coping of the individual members.

\section{Implications for Theory and Research}

The focus area of this study, volunteerism in healthcare, is under one of the social development agendas of communities, nations, and regions. The main contribution of this study is the conceptual framework that enhances our knowledge about the determinants of volunteerism and the mediating role of social network in healthcare volunteering sector. Prior to the involvement of individuals in volunteering activities, this study provides insights on the factors influencing philanthropic behavior among volunteers' involvement in health provision activities particularly based on a context of Malaysian non-governmental organization (NGO). These factors should be revealed, as it will benefit the NGOs in strategizing promotional and recruitment plan of new volunteers. Moreover, knowing all the possible constituents can be a 'golden key' for these NGOs to retain their existing volunteers. Hiring and conserving the right volunteers are vital for these NGOs as to reach the organizational objectives and to secure its survival over the long haul. Without doubt this study extends the Social Network Theory by clearly clarifies individual factors (task-oriented, emotional-oriented, avoidanceoriented coping, and social trust) that would broaden and strengthen up individual's social network through interaction and socialization process and to explain the volunteering activities among volunteers specialized in healthcare.

The TPB was used to support the SNT as the core theory used in the mediation analysis in this study. The findings revealed support for the employment of the TPB in the research framework of this study as the theory becomes the basis of using individual factors that influence behavioral outcome. It implies that individual social characteristics are important in enhancing what leads to volunteering activities in healthcare. Two essential qualities of those embark on in community healthcare volunteering activities are those with task-oriented coping, emotional-oriented coping, and those with broad social network.

\section{Implications for Practice}

The findings of this study will help MERCY Malaysia as well as any other stakeholders such as volunteer and charity work associations in healthcare that have similar functions and interests. For 
organizations to foster active volunteering engagement, they need to find volunteers that shared similar goals (Loiseau, et al., 2016). Therefore, the volunteering organization needs to develop a systematic hiring process to identify the most suitable individuals to be the next volunteers. Ample and appropriate training programs including induction program and other basic healthcare trainings (i.e., basic life support, aqua basic training, and emergency response) also must be provided to assist them in performing their volunteering work.

As predicted, individual differences in coping styles were differently associated with volunteerism in healthcare. As the result suggests, task-oriented and emotional-oriented coping both directly related to volunteerism. According to Savage (2005), these two coping styles are considered as proactive strategies and conventionally associated with better adjustment as reflected in higher self-rated coping effectiveness and less depression. Volunteers with task-oriented coping style tend to directly taking action upon any issues arose while executing volunteering work. All the knowledge and skills obtained will be integrated to ensure the task were completed in a healthy environment. Therefore, individuals with these characteristics should be attracted into the organization to be the future volunteers. This process of selecting the right individuals is very crucial particularly when assigning them to any humanitarian missions and emergency cases. Therefore, the results will enable MERCY Malaysia to develop community-based programs that are more attractive to their existing volunteers who are involved in various health provision activities for the purpose of community development.

In our study, task-oriented coping also indirectly influenced volunteerism through social network. Task-oriented individuals also known for their eagerness to seek for information, effective decisionmaker and planner, as well as a proficient conflict resolver. Inevitably, they will try various alternatives to obtain as much information as possible from colleagues inside and outside their social network to ensure consummation of a voluntary task given. Indirectly, they will increase the size of social network and increase their confidence in volunteer work they do.

The results of this study also able to help MERCY Malaysia and other NGOs that are trying to promote volunteering activities among non-medical background individuals to be involved in health provision activities. By identifying the factors influencing volunteers' involvement in healthcare volunteering activities, volunteer and charity work associations can focus lesser time and budgets in the hiring process. In addition, data of the fitted model offer managers, CEOs, and policy makers in volunteering institutions a guide to understand the crucial factors in attracting more volunteers into their medical relief activities (i.e., healthcare promotion, health education, cancer screening).

As a systematic understanding of volunteerism in Malaysia and detailed patterns and characteristics of Malaysian volunteers' behavior are still undeveloped, this study would contribute to a new vista towards understanding on such behavior, and could serve as a basis to monitor and assess non-profit volunteer organizations' programs in the community health-care sector. 


\section{Limitations and Future Directions}

With regard to the limitations of the study, we suggest the following directions for future research: First, this study was limited to volunteers from one single NGO (MERCY Malaysia). We therefore recommend future research to be extended to volunteers from other health-related NGOs in the country such as Malaysian Red Crescent Association. Second, future research could take into consideration other demographic and professional factors such as personality, educational attainment, gender, religiosity, and professional background. Third, future research is suggested to conduct social network analysis that focus on relationships between volunteers rather than attributes of volunteers. Finally, this research should be replicated to other countries in Asia and other regions in the world so that the results of which could be used for making comparison about the role of social network as a mediator on the influence of coping strategies and social trust with volunteerism in healthcare.

\section{Conclusion}

We have identified the mediating role of social network in the relationships between individual adaptability factors such as task-oriented coping and social trust with volunteerism in healthcare based on the TPB and SNT. We conclude that volunteers with high task-oriented coping would tend to display better philanthropic behaviour of volunteering through the mediating function of social network. Thus, interactive volunteering social system must be developed to encourage social networking among the volunteers.

\section{References}

Ahimbisibwe, A., \& Nangoli, S. (2012). Social networks: Mediator of project communication and perceived project success. International Journal of Humanities and Social Science, 2(20), 7385.

Ajzen, I. (1991). The theory of planned behavior. Organizational Behavior and Human Decision Processes, 50(2), 179-211.

Ajzen, I. (2005). Attitudes, Personality, and Behavior (2nd edition). New York: Open University Press.

Alias, S., \& Ismail, M. (2015). Antecedents of philanthropic behavior of health care volunteers. European Journal of Training and Development, 39(4), 277-297.

Arun, S., Annim, S., \& Arun, T. (2015). Do all networks 'work'? The mediating role of social networks on consumption expenditure in India. Sociology, June, 1-20.

Asendorpf, J. B., \& Wilpers, S. (1998). Personality effects on social relationships. Journal of Personality and Social Psychology, 74(6), 1531-1544.

Baron, R. M., \& Kenny, D. A. (1986). The moderator-mediator variable distinction in social psychological research: Conceptual, strategic, and statistical considerations. Journal of Personality and Social Psychology, 51(6), 1173-1182.

Bekkers, R., \& Bowman, W. (2009). The relationship between confidence in charitable organizations and volunteering revisited. Nonprofit and Voluntary Sector Quarterly, 38(5), 884-897.

Berkman, L. F., \& Glass, T. (2000). Social integration, social networks, social support, and health. In L. F. Berkman, \& I. Kawachi, Social epidemiology (pp. 137-173). New York: Oxford University Press. 
INTERNATIONAL JOURNAL OF ACADEMIC RESEARCH IN BUSINESS AND SOCIAL SCIENCES

Vol. 8, No. 12, Dec, 2018, E-ISSN: 2222-6990 @ 2018 HRMARS

Cattell, H. E. (2001). The sixteen personality factor (16PF) questionnaire." . Springer US, 2001. . In W. I. Dorfman, \& M. Hersen, Understanding psychological assessment (pp. 187-215). Springer US. Cheung, C.-K., Lo, T. W., \& Liu, E. S.-C. (2016). Sustaining social trust and volunteer role identity reciprocally over time in pre-adult, adult, and older volunteers. Journal of Social Service Research, 42(1), 70-83. Retrieved from http://dx.doi.org/10.1080/01488376.2015.1078267

Chow, W. S., \& Chan, L. S. (2008). Social network, social trust, and shared goals in organizational knowledge sharing. Information \& Management, 45(7), 458-465.

Cicognani, E., Pietrantoni, L., Palestini, L., \& Prati, G. (2009). Emergency workers' quality of life: The protective role of sense of community, efficacy beliefs and coping. Social Indicators Research, 94(3), 449-463.

Cohen, J. (1988). Statistical power analysis for the behavioral sciences. United States of America: Lawrence Erlbaum Associates.

Cordano, M., \& Frieze, I. H. (2000). Pollution reduction preferences of U.S. enviromental managers: Applying Ajzen's Theory of Planned Behavior. Academy of Management Journal, 43(4), 627641.

Cordano, M., \& Frieze, I. H. (2000). Pollution reduction preferences of US environmental managers: Applying Ajzen's theory of planned behavior. Academy of Management Journal, 43(4), 627641.

Courneya, K. S., Bobick, T. M., \& Schinke, R. J. (1999). Does the Theory of Planned Behavior mediate the relation between personality and exercise behavior? Basic and Applied Social Psychology, 21(4), 317-324.

Delhey, J., \& Newton, K. (2003). Who trusts?: The origins of social trust in seven societies. European Societies, 5(2), 93-137.

Department of Statistics Malaysia. (2016). Retrieved September 23, 2016, from Selected Demographic Estimates Malaysia 2016: https://www.statistics.gov.my/index.php?r=column/cthemeByCat\&cat=397\&bul_id=WVVQ UnYrZkRwK1k1QXZMbEpuV1hNUT09\&menu_id=LOpheU43NWJwRWVSZkIWdzQ4TIhUUT09

Do Something Good. (2012). Retrieved April 11, 2013, from http://dosomething.gd/

Endler, N. S., \& Parker, J. D. (1999). Coping Inventory for Stressful Situations (CISS): Manual (Revised Edition). Toronto: Multi-Health Systems, Inc.

Essex, B., \& Scott, L. B. (2008). Chronic stress and associated coping strategies among volunteer EMS personnel. Prehospital Emergency Care, 12(1), 69-75.

Finnigan, K. S., Daly, A. J., \& Che, J. (2013). Systemwide reform in districts under pressure: The role of social networks in defining, acquiring, using, and diffusing research evidence. Journal of Educational Administration, 51(4), 476-497.

Forthofer, M., Burroughs-Girardi, E., Stoisor-Olsson, L., Wilcox, S., Sharpe, P. A., \& Pekuri, L. M. (2016). Use of formative research and social network theory to develop a group walking intervention: Sumter County on the Move! Evaluation and Program Planning, 58, 28-34.

Fowler, J. H., \& Christakis, N. A. (2010). Cooperative behavior cascades in human social networks. Proceedings of the National Academy of Sciences of the United States of America, 107(12), 5334-5338.

Granovetter, M. S. (1973). The strength of weak ties. American Journal of Sociology, 78(6), 1360-1380. 
INTERNATIONAL JOURNAL OF ACADEMIC RESEARCH IN BUSINESS AND SOCIAL SCIENCES

Vol. 8, No. 12, Dec, 2018, E-ISSN: 2222-6990 @ 2018 HRMARS

Grove, J. R., \& Heard, N. P. (1997). Optimism and sport confidence as correlates of slump-related coping among athletes. The Sport Psychologist, 11, 400-410.

Hair, J. F., Black, W. C., Babin, B. J., Anderson, R. E., \& Tatham, R. L. (2005). Multivariate data analysis: Sixth Edition. Upper Saddle River, New Jersey: Pearson Education, Inc.

Hayes, A. F. (2009). Beyond Baron and Kenny: Statistical mediation analysis in the new millennium. Communication Monographs, 76(4), 408-420.

Hooper, D., Coughlan, J., \& Mullen, M. (2008). Structural equation modelling: Guidelines for determining model fit. Electronic Journal of Business Research Methods, 6(1), 53-60. Retrieved from http://arrow.dit.ie/cgi/viewcontent.cgi?article=1001\&context=buschmanart

Hult, G. T., Ketchen , D. J., Cui, A. S., Prud'homme, A. M., Seggie, S. H., Stanko, M. A., . . Cavusgil, S. T. (2006). An assessment of the use of structural equation modeling in international business research. In D. J. Ketchen, \& D. D. Bergh, Book Series: Research Methodology in Strategy and Management (pp. 385-415). Emerald Group Publishing Limited.

Iacobucci, D. (2008). Mediation Analysis. CA: Thousand Oaks.

Jinkyung, J., \& Eunsun, K. (2011). Trust development in volunteering an exploratory study of social trust and volunteer activities in Korea. International Review of Public Administration, 16(1), 157-179. doi:10.1080/12264431.2011.10805190

Kaeppler, A. K., \& Erath, S. A. (2016). Linking social anxiety with social competence in early adolescence: Physiological and coping moderators. Journal of Abnormal Child Psychology, 114.

Kaskutas, L. A., Bond, J., \& Humphreys, K. (2002). Social networks as mediators of the effect of alcoholics anonymous. Addiction, 97(7), 891-900.

Katz, N., Lazer, D., Arrow, H., \& Contractor, N. (2004). Network theory and small groups. Small Group Research, 35(3), 307-332.

Kelly, D. C. (2009). In preparation for adulthood: Exploring civic participation and social trust among youn minorities. Youth \& Society, 40(4), 526-540.

Lazarus, R. S. (1991). Emotion and adaptation. New York: Oxford University Press.

Loiseau, B., Sibbald, R., Raman, S. A., Darren, B., Loh, L. C., \& Dimaras, H. (2016). Perceptions of the role of short-term volunteerism in international development: Views from volunteers, local hosts, and community members. Journal of Tropical Medicine, 2016, 1-12.

Lu, Y., Zhou, T., \& Wang, B. (2009). Exploring Chinese user's acceptance of instant messaging using the theory of planned behavior, the technology acceptance model, and the flow theory. Computers in Human Behavior, 25(1), 29-39.

Manning, M., \& Bettencourt, B. A. (2011). Depression and medication adherence among breast cancer survivors: Bridging the gap with the theory of planned behaviour. Psychology and Health, 26(9), 1173-1187.

McPherson, M., Smith-Lovin, L., \& Cook, J. M. (2001). Birds of a feather: Homophily in social networks. Annual Review of Sociology, 27, 415-444.

McWilliams, L. A., Cox, B. J., \& Enns, M. W. (2003). Use of the coping inventory for stressful situations in a clinically depressed samle: Factor structure, personality correlates, and prediction distress. Journal of Clinical Psychology, 59(4), 423-437.

MERCY Malaysia. (2016). Retrieved June 24, 2016, from http://mercy.org.my/about-us/our-history/ 
INTERNATIONAL JOURNAL OF ACADEMIC RESEARCH IN BUSINESS AND SOCIAL SCIENCES

Vol. 8, No. 12, Dec, 2018, E-ISSN: 2222-6990 @ 2018 HRMARS

Morrison, E. W. (2002). Newcomers' relationships: The role of social network ties during socialization. Academy of Management Journal, 45(6), 1149-1160.

Nour, D. (2011). Relationship Economics: Transform Your Most Valuable Business Contacts into Personal and Professional Success. New Jersey, USA: John Wiley \& Sons, Inc.

Pavlova, M. K., \& Silbereisen, R. K. (2014). Coping with occupational uncertainty and formal volunteering across the life span. Journal of Vocational Behavior, 85(1), 93-105.

Preacher, K. J., \& Hayes, A. F. (2004). SPSS and SAS procedures for estimating indirect effects in simple mediation models. Behavior Research Methods, Instruments, \& Computers, 36(4), 717-731.

Preacher, K. J., \& Kelley, K. (2011). Effect size measures for mediation models: quantitative strategies for communicating indirect effects. Psychological Methods, 16(2), 93-115.

Rothmann, I. (2011). Retrieved from Kappa-squared: Mediation Effect Size: http://stats.myresearchsurvey.com/kappasquared/

Rothstein, B., \& Uslaner, E. M. (2005). All for all: Equality, corruption, and social trust. World Politics, 58(1), 41-72.

Savage, S. (2005). Retrieved September 26, 2016, from Task-oriented versus emotion-oriented coping strategies: The case of college students: http://www.redorbit.com/news/health/141147/taskoriented_versus_emotionoriented_cop ing_strategies_the_case_of_college_students/

Schumacker, R. E., \& Lomax, R. G. (2010). A beginner's guide to structural equation modeling. New York: Routledge.

Siegrist, M., \& Cvetkovich, G. (2000). Perception of hazards: The role of social trust and knowledge. Risk Analysis, 20(5), 713-719.

Stukas, A. A., Hoye, R., Nicholson, M., Brown, K. M., \& Aisbett, L. (2016). Motivations to volunteer and their associations with volunteers' well-being. Nonprofit and Voluntary Sector Quarterly, 45(1), 112-132.

Stukas, A. A., Snyder, M., \& Clary, E. G. (2016). Understanding and encouraging volunteerism and community involvement. The Journal of Social Psychology, 156(3), 243-255.

Van Ingen, E., \& Bekkers, R. (2015). Generalized trust through civic engagement? Evidence from five national panel studies. Political Psychology, 36(3), 277-294.

Westaby, J. D., Woods, N., \& Pfaff, D. L. (2016). Extending dynamic network theory to group and social interaction analysis Uncovering key behavioral elements, cycles, and emergent states. Organizational Psychology Review, 6(1), 34-62.

Wilson, J. (2000). Volunteering. Annual Review of Sociology, 26, 215-240.

Wing, S. C., \& Lai, S. C. (2008). Social network, social trust, and shared goals in organizational knowledge sharing. Information \& Management, 45(7), 458-465.

Yamagishi, T., Cook, K. S., \& Watabe, M. (1998). Uncertainty, trust, and commitment formation in the United States and Japan. American Journal of Sociology, 104(1), 165-194. 